\title{
Траектория жизненного пути в этнокультурном ландшафте енисейских старообрядцев (материалы к биографии К. И. Юрковой)
}

\author{
Галина В. Любимова
}

Институт археологии и этнографии СО РАН, Российская Федерация, Алена А. Стороженко

Тувинский государственный университет, Российская Федерация
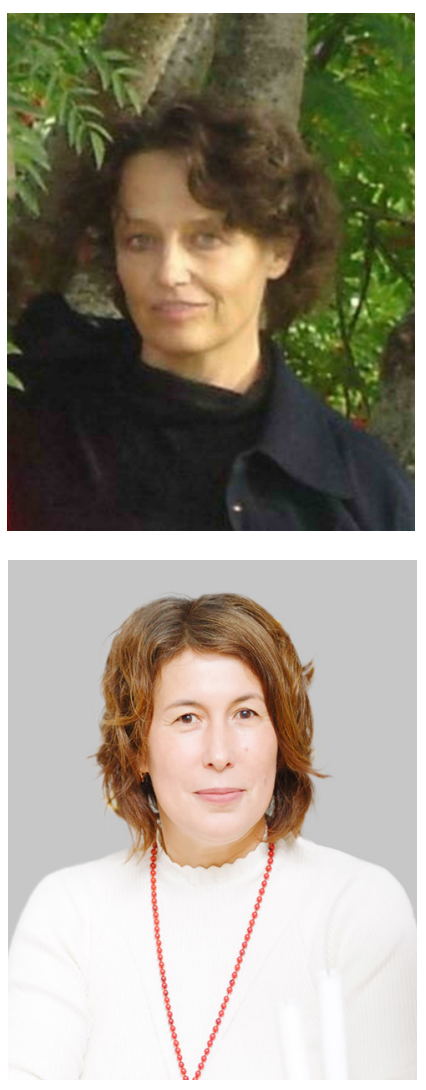

В статье показано, что тесное взаимодействие сакральных и профанных центров поселенческой структуры старообрядцев часовенного согласия на протяжении почти ста лет составляло основу этнокультурных ландшафтов «енисейского меридиана» - единого религиозно-экономического пространства, включавшего в себя современные территории Тувы и Красноярского края. На основе полевых материалов авторов, собранных в ходе экспедиционных поездок в места компактного проживания старообрядиеев-часовенных Верхнего и Нижнего Енисея 2004-2021 г2., а также архивных документов по истории старообрядческих миграций, в работе реконструированы основные вехи уникального жизненного пути Клавдии Ивановны Юрковой (по отиу Сальниковой), которая еще в юном возрасте была отдана в Дубчесский монастырь и прожила там двенадцать лет вплоть до его разорения в 1951 г.

Контент-анализ записанных в разные годы текстов интервью позволил выявить эмоционально окрашенные высказывания, характерные для биографического нарратива, и воссоздать значимые фрагменты системы ценностей информанта. Делается вывод, что траектория земной жизни старообрядиев-часовенных, рассмотренная на фоне миграционных процессов, является проекцией их духовной жизни как пути к спасению.

Ключевые слова: биографический нарратив; персональная история; этнокультурный ландшафт; конфессиональная миграция; старообрядцы Енисея; старообрядцы Тувы; Тува; часовенное согласие; религиозное пространство

Для цитирования:

Любимова Г. В., Стороженко А. А. Траектория жизненного пути в этнокультурном ландшафте енисейских старообрядцев (материалы к биографии К. И. Юрковой) // Новые исследования Тувы. 2021, № 3. С. 75-89. DOI: https:// www.doi.org/10.25178/nit.2021.3.6

Любимова Галина Владиславовна - кандидат исторических наук, старший научный сотрудник Отдела этнографии Института археологии и этнографии Сибирского отделения РАН. Адрес: 630090, Россия, г. Новосибирск, пр. Академика Лаврентьева, 17, каб. 403. Тел.: +7 (383) 330-05-37. Эл. адрес: terra-gl@mail.ru

Стороженко Алена Александровна - кандидат исторических наук, доцент кафедры Отечественной истории Тувинского государственного университета. Адрес: 667000, Россия, г. Кызыл, ул. Ленина, д. 5 . Тел.: + 7 (394-22) 2-21889. Эл. адрес: alstorozhenko@yandex.ru

LYUBIMOVA, Galina Vladislavovna, Candidate of History, Senior Research Fellow, Department of Ethnography, Institute of Archaeology and Ethnography, Siberian Branch, Russian Academy of Sciences. Postal address: Room 403, 17 Akademik Lavrentiev St., 630090 Novosibirsk, Russian Federation. Tel.+7 (383) 330-05-37. Email: terra-gl@mail.ruＯRCID ID: 0000-0003-3538-2806 STOROZHENKO, Alyona Aleksandrovna, Candidate of History, Associate Professor, Department of Russian History, Tuvan State University. Postal address 5 Lenin St., 667000 Kyzyl, Russian Federation. Tel.: +7 (394-22) 2-218-89. Email: alstorozhenko@yandex.ru ORCID ID: 0000-0001-9986-8966 
Article

\title{
Trajectories of a life journey in ethnocultural landscape of the Yenisei Old Believers: notes to the biography of K. I. Yurkova
}

\author{
Galina V. Lyubimova \\ Institute of Archaeology and Ethnography, SB RAS, Russian Federation, \\ Alyona A. Storozhenko \\ Tuvan State University, Russian Federation
}

\begin{abstract}
The article shows that for almost a hundred years, the ethnocultural landscapes of the "Yenisei Meridian" rested upon a close collaboration between the sacred and secular spaces of a settlement and its structure. The "Yenisei landscape" was a unified religious and economic space that existed in what now are territories of Tuva and Krasnoyarsk Krai. The field materials that formed the basis of the article were collected during the 2004-2011 expeditions to the areas populated by the Chasovennye accord of Old Believers. These, together with archival materials on the history of Old Believer migrations, helped us reconstruct the major events in the unique life journey of Klavdiya Ivanovna Yurkova (nee Salnikova) who was sent to live at the Dubsches monastery and stayed there for twelve years, until the monastery was disbanded in 1951.

Applying content analysis to interview texts accumulated over years helped reveal emotionally coloured phrases, typical for a biographical narrative and reproduce the crucial elements in the informant's value system. We conclude that the lifepath of the Chasovennye seen in the context of migration processes, appears as a projection of their spiritual life as a path to salvation
\end{abstract}

Keywords: biographical narrative; personal history; ethnocultural landscape; confessional migration; Yenisei Old Believers; Old Believers in Tuva; Tuva; Chasovennoe accord; religious space

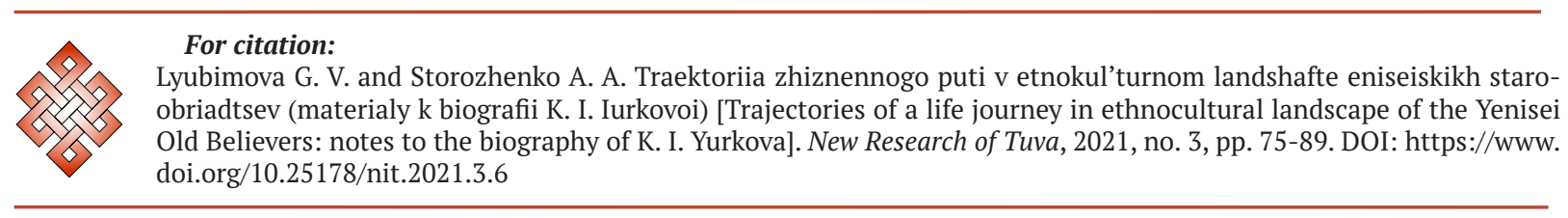

\section{Введение}

Из письма матушки Мастрадеи сестрам.

Будучи отличительной чертой старообрядческого мировоззрения и перманентным катализатором многих конфессиональных процессов, стремление к спасению души стимулировало представителей наиболее радикальных старообрядческих согласий регулярно сниматься с насиженных мест, заставляя искать новые, еще необжитые и более безопасные с точки зрения религиозной свободы пространства. Сам поиск «чистых», неподвластных антихристу мест, отвечавших, по сути, формуле «идеального ландшафта», рассматривался староверами как процесс обретения спасения. О топологии таких ландшафтов позволяют судить духовные стихи, в которых представлены описания «ухода из антихристова мира» «во темные леса, во далекие пустыни, во глубокие пещеры». Широкое распространение подобные идеи получили у северорусских и сибирских беспоповцев (Чистов, 2002: 180, 188; Любимова, 2017: 122), в том числе, староверов часовенного согласия, область расселения которых охватывает сегодня территории Тувы и Красноярского края, составляя единое религиозноэкономическое пространство, получившее в литературе название «енисейского меридиана» (Стороженко, 2019: 4). 
Благодаря труднодоступности и малонаселенности, глухие таежные места в бассейне Дубчеса (левого притока нижнего течения Енисея) стали прибежищем для старообрядцев, спасавшихся в 1930-1940-е гг. от коллективизации и преследования властей. Пережив в 1951 г. тщательно спланированную операцию по разорению и уничтожению скитов (Герасимов, 1991; Покровский, 1992; Покровский, Зольникова, 2002: 28-57), старообрядческая община смогла восстановить свою поселенческую структуру. В настоящее время Дубчесские скиты являются признанным духовным центром старообрядцев-часовенных. Еще одним местом компактного расселения часовенных стали верховья Малого Енисея (так называемое Верховьё), где уже в первой половине XX в. было основано немало скитов и поселений (там же: 7-8; Стороженко, Татаринцева, 2016; Стороженко, Татаринцева, 2019). Концепт «за Саянами», получивший широкое распространение в постсоветский период, актуализировал представления об обособленности мира тувинского старообрядчества, социальное и культурное развитие которого оказалось локализованным в относительно замкнутом географическом пространстве (Ламажаа, 2012: 280-283).

Рассмотрению вариантов траекторий жизненного пути старообрядцев-часовенных на фоне миграционных процессов и посвящена настоящая статья.

Тайные или, как минимум, не организованные и неконтролируемые официальными властями переселения достаточно больших групп конфессиональных мигрантов являлись повседневной практикой освоения сибирских пространств. Исчезновение из неполных и порой далеко не точных статистических источников конфессиональной графы затрудняет оценку возможных масштабов и объемов переселений. Перекрестный анализ, тщательное сопоставление разных источников и просто исследовательский опыт с опорой на полевые материалы, прежде всего, личные сведения о пофамильном и посемейном составе поселенцев - вот те методы, которые позволяют реконструировать историю формирования этнокультурных ландшафтов Верхнего и Нижнего Енисея на основе конфессиональных перемещений, происходивших в тесном взаимодействии мирских и скитских общин. В то же время изучение жизненного пути старообрядцев-часовенных на фоне религиозных миграций предполагает опору на дополнительные методы исследования, в первую очередь, связанные с анализом биографических нарративов, полученных в ходе структурированных интервью.

Интервью записаны в ходе нескольких экспедиционных поездок, начиная с 2004 по 2021 годы, в места компактного проживания старообрядцев часовенного согласия Республики Тыва авторами настоящей статьи.

На материале биографических нарративов, записанных в ходе экспедиционных поездок, а также архивных материалов в работе воссозданы основные вехи уникального жизненного пути и реконструированы социальные связи Клавдии Ивановны Юрковой (по отцу Сальниковой), которая еще в юном возрасте была отдана в Дубчесский монастырь и прожила там двенадцать лет вплоть до его разорения в 1951 г. Особое внимание уделено истории семейного клана Сальниковых, бежавших из Перми в Сибирь, спасаясь от коллективизации и религиозных преследований.

\section{Обзор литературы, научная гипотеза и методическая база}

Общинный характер старообрядческих поселений, сохраняющийся у часовенных Сибири вплоть до настоящего времени, их ориентация на «свой» собор, принадлежность к которому обеспечивает непрерывность конфессиональной практики и преемственность обрядов жизненного цикла, во многом предопределили и способы их переселения. Как правило, старообрядцы перемещались группой родственных семейных кланов, целыми монастырями, скитскими коллективами и очень редко - по одиночке. На макроуровне миграции пермского, вятского, поволжского и уральского старообрядчества в Сибирь, а также отдельные микроисторические сюжеты изучены с разной степенью полноты в коллективных монографиях «На путях из Земли Пермской в Сибирь» (На путях ... , 1989), «Сибирь и Русский Север» (Сибирь и Русский ..., 2014), в работах Г. Н. Чагина (Чагин, 1998), К. В. Чистова (Чистов, 2002), Ю. В. Аргудяевой (Аргудяева, 2001), А. В. Черных (Черных, 2001), Л. Н. Приль (Приль, 2001), Е. Е. Дутчак (Дутчак, 2007) и др.

Складывание сети мирских поселков и скитов часовенных старообрядцев на территории Тувы и Красноярском крае в середине XX в. реконструировано в исследованиях Н. Н. Покровского и Н. Д. Зольниковой (Покровский, 1991, 1992; Покровский, Зольникова, 2002). Опираясь на материалы Урало- 
Сибирского патерика ${ }^{1}$ они рассмотрели основные направления миграций часовенных и их скитов с Урала на р. Чулым в 1892 г., а впоследствии в Колыванскую тайгу в 1917 г. на границу современных Томской и Новосибирской областей (Зольникова, 1998: 176). Также в этот период осколок скита о. Нифонта во главе с о. Игнатием появился в Туве (Покровский, Зольникова, 2002: 29).

По справедливому мнению Е. Е. Дутчак, назрела необходимость смены или, как минимум, уточнения категориального аппарата и создания модели конфессиональной миграции, которая могла бы системно представить объективные условия и субъективные предпосылки, позволявшие человеку сначала оставить знакомые и родные места, а потом считать свое переселение состоявшимся и ненапрасным (Дутчак, 2007: 23). Различные аспекты скитской колонизации (на примере западносибирских территорий странников, часовенных и безотчетливых) на рубеже XIX-XX вв., ее причины, факторы и результаты подробно рассмотрены в ряде ее работ (Дутчак, 2011).

История складывания в Сибири и в Туве сети скитов часовенных староверов во взаимодействии с мирской округой, их перемещения, внутреннего устройства по состоянию на середину XX в. в общих чертах нашли отражение в работах тувинских исследователей (Татаринцева, 2006; Татаринцева, Стороженко, 2015; Стороженко, 2015; Стороженко, Татаринцева, 2019: 95). Повседневные религиозные практики часовенных в рамках народного календаря и семейной обрядности рассматривались Г. В. Любимовой (Любимова, 2004) и Е. С. Данилко (Данилко, 2019).

Несмотря на пристальное внимание исследователей, тесное взаимодействие скитов и мирских общин в контексте сибирских миграций староверов-часовенных на микроисторическом уровне изучено недостаточно.

Мы полагаем, что условием устойчивости старообрядческих социумов таежных районов Западной и Восточной Сибири являлись особенности этнокультурных и конфессиональных ландшафтов, генерируемые не просто путем сохранения в их повседневности дуальной связки «скит-деревня», но и за счет сочетания процессов скитской колонизации и крестьянских переселений на основе общей социально-экономической и духовной жизни скитских и мирских общин. Отметим, что значимость религиозного ландшафта именно для урало-сибирских территорий, как пишут уральские историки Е. М. Главацкая и И. Л. Манькова, определяется ключевой исторической проблемой Урала и Сибири, связанной с их перманентным освоением, поскольку религиозный ландшафт как никакая другая категория позволяет проследить, как осваивалось и развивалось то или иное место, усваивая или отвергая то, что привносилось извне переселенческими волнами르 (Главацкая, 2008: 77-79; Манькова, 2008: 83).

Вместе с тем, методология изучения конфессиональных миграций, ограничивающаяся анализом их причин и факторов, а также условий и показателей, на современном этапе не дает адекватного описания внутренних мотивов и персональной истории переселений «человека культурного» (Дутчак, 2006: 86). По этой причине в качестве теоретической рамки исследования нами выбран подход, условно обозначенный как новая биографическая / персональная история, базовой задачей которого является восстановление персонального жизненного пути во всей множественности линий его развития, реализация которых во многом зависит от собственного выбора человека. Указанный ракурс исследования, говоря словами Л. П. Репиной, позволяет показать, каким образом личная жизнь и судьбы конфессиональных мигрантов, «формирование и развитие их внутреннего мира, следы их деятельности в разномасштабных промежутках пространства и времени выступают... как адекватное

\footnotetext{
${ }^{1}$ Урало-Сибирский патерик - обширное историко-агиографическое сочинение, созданное в конце $1940-\mathrm{x}-$ начале 1990-х гг. писателями-старообрядцами крупнейшего на востоке России часовенного согласия (УралоСибирский ..., 2014).

${ }^{2}$ В этой связи томские исследователи подчеркивают, что изучение православного ландшафта таежной Сибири XIX - начала XX в. должно включать в себя «не только имперский образ распространяющегося вширь православия», но и отличные от «официального варианта христианской доктрины... старообрядческие пространственные мифологемы», такие, как Беловодье, «земной рай», «чистые / святые места» и пр. (Дутчак и др., 2013: 81). Ценным источником по истории формирования социальной инфраструктуры томско-чулымской тайги начала XX в. при этом могут служить переселенческие карты, подготовленные Переселенческим управлением Главного управления землеустройства и земледелия, в которых нашли отражение особенности не только крестьянской, но и скитской колонизации региона, включая локализацию скитов староверов страннического, часовенного и белокриницкого согласий, а также расположенных вокруг них заимок (Васильев, Ким, Буркун, 2016: 799).
} 
средство познания... исторического социума» (Репина, 2005: 56) и тем самым могут использоваться «для прояснения социального контекста» (там же: 285-286).

\section{Пермский след}

В этнокультурном и конфессиональном отношении старообрядцы Пермского края не были единым массивом. В Томскую область и далее на восток из Южного Прикамья в исследуемый период переселялись старообрядцы юго-западной его части, включавшей в себя выходцев из разных волостей Осинского уезда Пермской губернии, что соответствует современным Еловскому, Чайковскому, Куединскому, частично Бардымскому и Осинскому районам современного Пермского края (Черных, 2002: 135-136).

Общая численность старообрядческого населения одного только Осинского уезда за вторую половину XIX в. выросла более чем в 2,5 раза и составила 26578 человек (63,8\% всего старообрядческого населения региона). Субконфессиональный состав юго-западной группы был разнообразный, включая расселенных дисперсно старообрядцев белокриницкого, поморского и страннического согласий, однако большую часть среди них составляли часовенные (там же: 137, 139).

B середине XIX в. в Сибири и на Дальнем Востоке проживало немало старообрядцев - выходцев из Пермской губернии. Но если в 1885-1889 гг. в общем переселенческом потоке пермяки занимали второе по численности место, то к 1900-1904 гг. они переместились уже на двадцатое место (Аргудяева, 2001: 259; Фурсова, 2014: 102). Последователи старой веры, составлявшие не менее одной трети от общего числа пермских переселенцев, расселились практически по всей зауральской территории. Хозяйственно-статистическое обследование крестьянских волостей Алтайского округа, проведенное Н. А. Вагановым в начале $1880-$ х гг., показало преобладание в нем пермских переселенцев - выходцев из Чердынского, Осинского, Соликамского и других уездов (Ваганов, 1882).

В течение второй половины XIX - первой трети XX в., как пишет Л. Н. Приль, «в одном из районов Томской обл. сложилась зона компактного проживания старообрядцев-пермяков, где кроме них не было другого населения» (Приль, 2001: 254). Речь идет о междуречье притоков Оби - рек Улуюла и Чичкаюла - условно именуемом Заимочным районом, удаленном от населенных пунктов и не имевшем (даже в конце 1920-х годов) точной административной привязки. Территориально этот район, расположенный на востоке Томской области, граничит с Красноярским краем, будучи связанным с ним Обь-Енисейским каналом. К моменту проникновения сюда староверов он не был заселен и освоен. В междуречье рек Улуюла и Чичкаюла часовенными старообрядцами был создан своего рода плацдарм для дальнейшего проникновения на р. Кеть (там же: 251) и в долину р. Безымянка.

Согласно похозяйственным книгам, отложившимся в Енисейском районном архиве Красноярского края, семья пермских староверов Сальниковых, выехавшая примерно в 1930 г. из с. Малая Уса Усинского р-на Пермской области (Стороженко, 2019: 8), до 1939 г. проживала на территории Чичкаюльского сельсовета Тегульдетского района Томской области (Енисейский районный архив - EPA, ф. 153, оп. 2, д. 7, л. 110). Мотивы внезапного переселения на столь дальнее расстояние носили, безусловно, как внешний, так и внутренний, сугубо конфессиональный характер. Можно определенно утверждать, что причины эти лежали не только в экономической плоскости. По словам самой Клавдии Ивановны, на начало переселений ей было совсем мало лет:

«Да что я помню, в четыре года поехали. А раньше, по рассказам, неплохо жили... / Родители наши все из Россеи, какая-то Молотовская область ${ }^{1}$, мама вспоминала...» (Полевые материалы авторов - ПМА, 2014 г., 2021 г., п. Сизим Каа-Хемского р-на Республики Тыва).

Родственники матери - Агафьи Александровны Сальниковой (в девичестве Кобелевой) по крестьянским меркам были довольно зажиточными:

«...вели торговлю... сеяли для себя и корову держали для себя... Рыба ищет, где глубже, а человек - где лучше», - подумав, добавила собеседница (там же).

Затем Сальниковы перебираются в Красноярский край. Видимо, именно в этот момент умирает отец семейства. Клавдия Ивановна свидетельствует, что при переезде жить лучше не стали:

«В Сибирь переезжали по маленьким селам, там отец и заболел, поздно привезли в больницу... Лучше не жили. До меня умерли два парня и две девки. Из четырех сестер, что выжили, я - вторая» (ПМА, 2021 г., п. Сизим).

\footnotetext{
${ }^{1}$ Пермская область с 8 марта 1940 г. по 2 октября 1957 г. называлась Молотовской областью.
} 
Согласно «Спискам временно пребывающих», семья Сальниковых в составе Агафьи Александровны (1889 г. р.) и трех дочерей - Любови (1925 г. р.), Клавдии (1926 г. р.) и Устиньи (1930 г. р.) - в 1939 г. была поставлена на учет в Луговатском сельсовете Енисейского р-на Красноярского края. Поражает протокольная точность документа, в котором зафиксировано, что на территории сельсовета Сальниковы проживали полтора месяца - с 26 июня до 9 августа (ЕРА, ф. 153, оп. 2, д. 7, л. 110).

Далее семья постоянно переезжает из одного поселка в другой, реализуя довольно распространенный для того времени сценарий поразительной внутренней миграционной мобильности. Находясь уже на территории региона, староверы (о которых сибиряки-старожилы говорили, что они «текучи, как вода» и никогда «не сидят на месте»), с легкостью могли перемещаться не только в пределах одного района, но и на многие сотни километров, заботясь только об одном - чтобы был «свой собор». Уже в наши дни современные обитатели старообрядческих поселков объясняют эту неуемную потребность в постоянных переселениях как необходимость следовать принципу, согласно которому нельзя «на одном месте долго жить - забогатеешь, а богатство-то ить - грех» (ПМА, 2018 г., п. Сизим). Известны случаи, когда отдельные староверческие семьи в течение жизни могли переселяться более 50 раз, причем впечатляет сама география переселений - от Северной Америки до Урала, далее на Дальний Восток, на Енисей и опять на Дальний Восток.

В 1940 г. (год рождения Агафьи Александровны явно исправлен на 1902-й) семья значится в списке единоличников с. Безымянка Луговатского сельсовета. Помимо уже упомянутых дочерей - Любови (1925 г. р.), Клавдии (1926 г. р.) и Устиньи (1930 г. р.), в списке отмечена внучка Агафьи Александровны Фаина Григорьевна (1938 г. р.). Позднее чернилами другого цвета приписана старшая дочь Лидия (1919 г. р.). На двух гектарах земли у Сальниковых посеяны озимая рожь, горох и лен. Из скота только одна корова и телка. Держали и улья - семь пчелосемей. Кроме того, имелись дом, хлев и баня (все постройки - до 1935 г.) (ЕРА, ф. Р-277, оп. 2, д. 12, лл. 45 об.-46). Примечательно, что напротив имени Клавдии Ивановны стоит приписка - «живет у сестры» (там же: л. 46), хотя в то время она уже находилась в скиту у матушки Флены на Безымянке и готовилась перебираться на Дубчес (Стороженко, 2019: 8).

Позже, но тоже в 1940 г., семья уже числится в составе единоличных хозяйств д. Тарасово того же Луговатского сельсовета (ЕРА, ф. Р-277, оп. 2, д. 13, лл. 67 об.-68). Отмечено, что Сальниковы посеяли горох, рожь, лен, имели три пчелиных улья. Интересно, что в новом списке год рождения Агафьи Александровны вновь указан как 1902-й, у Лидии 1919-й исправлен на 1920-й, у Любови 1924-й исправлен на 1925-й, у Устиньи оставлен прежний (1930-й) и у внучки Фаины появляется фамилия Балабанова. У самой Агафьи Александровны указан муж Булачев Григорий Петрович (1893 г. р.), позднее вычеркнутый из списка. Что касается дочери Клавдии, то она совсем исчезает из состава семьи (там же: лл. 67 об.-68).

Всего в д. Тарасово, находившейся в 16 км от Луговатки, на тот момент в 20 хозяйствах проживало 63 жителя (ЕРА, ф. Р-277, оп. 1, д. 4, л. 5). Из всех населенных пунктов Луговатского сельсовета это была одна из самых малонаселенных деревень (ЕРА, ф. Р-277, оп. 1, д. 4, л. 21). Наиболее крупными по числу жителей были сама Луговатка (247 чел.), Низ-Безымянка (229 чел.), Якша (205 чел.) и Ключи (156 чел.) (ЕРА, ф. Р-277, оп. 1, д. 4, л. 6). В материалах судебно-следственного дела о разгроме Дубчесского монастыря в 1951 г. д. Тарасово часто упоминается как поселение единоличников, в котором велись беседы о безбожности советской власти, в том числе, о. Симеоном и другими отцами и матушками.

В 1945 г., накануне отъезда из Безымянки в Ворогово (что отмечено в документе), семья значится в том же составе, но год рождения Агафьи Александровны снова указан как 1889 г. Помечено, что Лидия учится в 3-ем классе, Любовь и Устинья - во 2-м. Помимо ржи, гороха и льна посеяны ячмень, пшеница, картофель и овощи. Из скота отмечена одна корова, кроме того, упомянуты курицы (EPA, ф. Р-277, оп. 2, д. 28, лл. 7 об.-8). С момента отъезда в 1939 г. двенадцатилетней дочери Клавдии в Дубчесский монастырь ее семья уже постоянно проживала на Луговатке, в пределах одного Енисейского р-на. Известно, что мать навещала ее лишь единожды.

К 1944 г. Луговатский сельсовет административно перешел из Енисейского района в Ярцевский. В годы войны он представлял собой густонаселенную сеть из 23 населенных пунктов (EPA, ф. P-277, оп. 1, д. 4, л. 21). Из общей численности населения, составлявшей 1849 чел., на долю единоличников приходилось примерно две трети (1278 чел.), соответственно, из 562 хозяйств колхозные хозяйства составляли всего 111 (ЕРА, ф. Р-277, оп. 1, д. 4, л. 4). На 1 января 1945 г. в Луговатском сельсовете было зафиксировано 1916 чел., из них большинство единоличников - 1329 чел. Общее число хозяйств возросло до 587. Из них единоличными оставались 427 хозяйств. (ЕРА, ф. Р-277, оп. 1, д. 4, лл. 4-22). 
По данным Л. Н. Приль, «миграционная волна, перекатывавшаяся через междуречье (рек Улуюла и Чичкаюла. - Г. Л., А. С.), насчитывала сотни человек, о чем органы советской власти на местах не имели точных сведений» (Приль, 2001: 254). Анализ документов Госархива Томской области и материалов Томского краеведческого музея позволил автору прийти к выводу, что старообрядческие «пермские общины проявили на томской земле высокую адаптационную одаренность и реализовали большой созидательный потенциал» (там же: 254). Приведенные выше архивные данные свидетельствуют также об успешной хозяйственной деятельности пермских старообрядцев и на территории Красноярского края. К 1 июня 1944 г. в Луговатском сельсовете имелось 623 головы крупного рогатого скота, из них 427 принадлежало единоличникам. Подавляющее число лошадей (34 из 36) и более половины овец (286 из 442 голов) также находилось в единоличных хозяйствах (EPA, ф. Р-277, оп. 1, д. 4, л. 15-15 об.).

Скитские общины часовенных имели шанс сохранить хозяйственный потенциал и закрепиться на новом месте при одном условии - активном участии на всех этапах переселения крестьян-единоверцев. Защита и покровительство сельской округи были жизненно необходимы небольшим обителям. Отсюда вытекала важная особенность поселенческой структуры староверов-часовенных - их обители располагались вблизи тех населенных пунктов, где жили единоверцы. Это облегчало открытие новых скитов, перемещение действующих и сохранение во времени и пространстве традиционных связей между монастырем и сельской округой, включая благотворительность, найм, а также трудовой или имущественный вклад (Дутчак, 2011). Всего в течение 1930-1950-х гг. на Дубчесе и его притоках Керженке, Дунчесе, Большом Тогульчесе, Малом Тогульчесе, а также на реках Безымянка, Ломоватка, Вороговка, Кас, Сым и Моховка было основано более десятка скитов.

Мирские поселения первоначально возникали в виде куста заимок, разбросанных на небольшом отдалении от духовных центров - скитов, которые располагались по преимуществу на территории Луговатского сельсовета. Постепенно заимки превращались в деревни, изредка - в села, наиболее крупные из которых (Сым, Сандакчес) становились факториями. По мере обживания на новом месте на случай преследований было принято решение основать в районе новые скитские поселения, но теперь уже на значительном расстоянии от мирских поселений. При этом связь, поддержка и защита скитов со стороны последних были постоянными.

Необходимость тесной «взаимопомощи и даже взаимопроникновения» между скитами и крестьянскими поселениями, обозначенная Н. Н. Покровским и Н. Д. Зольниковой как «система симбиоза» (Покровский, Зольникова, 2002: 51-52), диктовалась потребностями обеих сторон.

Будучи носителями особой миссии спасения, скитники осознавали себя в качестве попечителей духовной жизни единоверцев, проживавших в сельской округе. В то же время материальное обеспечение самих скитов в значительной степени зависело от помощи единоверцев-мирян (так называемых «христолюбов»). По этой причине взаимодействие между скитскими и крестьянскими поселениями рассматривается в научной литературе как вариант народно-православной традиции дарообмена (Дутчак, Ким, Буркун, 2015: 236). Отношения «скит - деревня» выступают при этом как своего рода дуальная система или особая социально-символическая конструкция, главная функция которой заключается в обеспечении равновесного состояния ее сакральной и профанной частей.

\section{Путь к спасению}

По мнению Е. Е. Дутчак, к середине XX в. «сакральная карта» таежных монастырей представляла собой совокупность одиночных и групповых поселений - пу́стыней. Каждая пустынь считалась наиболее защищенным от антихриста местом, которое наделялось чертами райской обители, отождествлялось старообрядцами с раем (Дутчак, 2007: 146-147). Вместе с тем, как обращает внимание Н. Н. Покровский, традиции крестьянского пустынничества вобрали в себя не только «извечную крестьянскую тягу» к освоению новых мест, но и традиционно христианское стремление к монашеской аскезе. Проживание «вдали от раздоров и соблазнов шумного мира... в долгих молитвах и в тяжких трудах для пропитания братии и захожих паломников» расценивалось при этом как спасение души (Покровский, 1992: 194-195).

Непростое решение о переселении принималось каждой старообрядческой общиной под влиянием конкретных обстоятельств (Приль, 2001: 249). Однако главные цели, мотивы и результаты переселения заключались в том, чтобы сохранить собор, общину и конфессиональную жизнь в целом. 
Восприятие социально-политической обстановки 1930-х гг. как социоприродной катастрофы, нашедшее отражение в «Прощальном письме при гробнице отца Савы, пред отъездом в пределы реки Енисея» ${ }^{1}$, позволяет прояснить мотивы переселения мужских часовенных скитов в Сибирь. Авторы письма сообщают об «ужасно разбушевавшейся темной туче безбожия», «разрушении всего строя християнской жизни» и о том, что сами старообрядцы оказались «в плену незнающих Бога»:

«...весь мир волнуется, християнское сословие разъезжаются, наступили лютые, предсказанные плачевные времена, в которых Церковь Христова побегнет в глубочайшую пустыню..., носящи терпения вожделенный крест пресладкого Исуса. Вот ето-то обстоятельство подвигло и нас к поездке, честнейший отче... (невольно заставляя) разлучаться от твоея святолепныя гробницы» (Духовная литература ... , 1999: 214).

Прямо сформулированная в тексте принципиальная установка на пустынножительное существование передается через обращенную к Небесному Владыке мольбу направить своих чад «в нарочитую безмолвную пустыню»: «Возведи окрест очи твои и виждь, се бо приидоша к тебе... чада твоя, в пустыни благословяща Христа вовеки» (там же: 214).

Женские скитские поселения, не столь многочисленные, как мужские, имели порой меньше шансов на выживание, как следует из описания истории переселения скита матери Тавифы:

«...время (настало) жуткое, мир весь заволновался, кто куда поехали. Тогда вспомнили слова отца Савы, что молодым близ мира жить неполезно. Хотя раньше и никогда не думали куда-то ехать, // но сразу надумали, что не примет ли нас отец Сава под свое крило попечение... А мать Тавифа когда приехали к отцу Саве, и он приветил их и не отринул, но сказал так, что “не кланяйтесь, Бога просите, Бог управит. И я уже стар, а братия у меня еще молодые, и пещися о вас некому будет» (Урало-Сибирский ..., 2014: 201).

В «Родословной старицъ» ${ }^{2}$ подробно описаны места скитских поселений - три «отрасли» (кунгурская, сунгульская и алтайская или ашпанакская), тесно связанные, но до слияния на Дубчесе в конце 1930-х гг. существовавшие отдельно. Там же отмечено, что уральские женские часовенные скиты под управлением игуменьи инокини схимницы Феодоры, а после нее - инокини схимницы Зинаиды и инокини Венедикты, располагавшиеся в Кунгурском уезде «деревни Кедровки, недалеко от реки Сылвы на Зарослой... переместились в Ялуторовские пределы Тобольской губернии, к Калмыковым» (там же: 171).

Все их дальнейшее переселение осуществлялось уже совместно с мужскими скитами: «А когда отец Сава с братией поехали от Калмыковых на Чулым, тогда и мать Мелетина с сестрами туда же переселились. А потом с Чулыма переехали на Парбик... и они пришли под управление матере Тавифы Сунгульской» (там же: 172). Известно, что мать Тавифа (Татьяна Михайловна Людиновскова) по рождению была родной сестрой отца Антония (там же: 316). Вначале «сунгульские старицы... переселились с Сунгула в деревню Солобоево», затем - «на реку Танаевку... потом на реку Тавангу и на Парбик, а оттуда на Безымянку» (там же: 173). Причем расставание с обжитыми, с трудом отвоеванными у тайги местами воспринималось старообрядцами как «изгнание из рая» («Оставили вы прекрасную пустыню и премилой Сунгульский край, а он точно как едемский рай») (Журавель, 2001: 56).

Ашпанакская «отрасль» образовалась после разделения сунгульской, когда Мелетина Сунгульская уехала на Чулым, а «мать Александра с оставшимися сестрами...преселися на Черную гору», потом на Лаю, и вскоре одна часть скита с матерью Александрой уехала сначала на Танаевку и через Тавангу на Парбик и Безымянку (Урало-Сибирский ..., 2014: 173), а другая с матерью Елизаветой после Лаи «уехала за Бийск в деревню Ашпанак. И потом тут пришла мать Флина, от нея и получила иноческий чин» (там же: 174). Вскоре обитель распалась и мать Флина, получившая на Урале благословение, переселилась на Парбик (там же: 320; Стороженко, 2019: 8), откуда она переехала на Безымянку и потом на Дубчес (Урало-Сибирский ..., 2014: 174).

С этим монастырем и была связана дальнейшая судьба Клавдии Ивановны, которая, по ее словам, «в монастырь пошла в 12 лет по своей воле и пробыла там 12 лет» вплоть до его разорения в 1951 г. (ПМА, 2021 г., п. Сизим). Само разорение, ставшее одним из наиболее травматических событий ее жизненного пути, спустя более полувека представлено ею следующим образом:

1 «Прощальное письмо при гробнице отца Савы, пред отъездом в пределы реки Енисея» - произведение староверов часовенного согласия, хранящееся в собрании Института истории СО РАН, № 4 / 90-г, л. 86 об.-88 об. (Духовная литература ..., 1999: 213-214).

2 «Родословна старицъ» - произведение староверов часовенного согласия, хранящееся в собрании Института истории СО РАН, № 11 / 90-г, л. 1-138 (Урало-Сибирский ..., 2014: 171-276). 
«...отцы-настоятели были расстреляны сразу ${ }^{1}$, а остальных погрузили на плоты и повезли вниз по Дубчесу, сначала в Енисейск, потом в Красноярск. Многие тогда бросались с плотов, чтобы погибнуть. Старших забрали в тюрьмы, отец Симеон и матушка Маргарита там в тюрьме и умерли» (ПМА, 2004 г., п. Сизим; Любимова, 2004: 53).

По словам священноинока Евагрия (1982 г. р.), имевшего опыт проживания и на Нижнем, и на Верхнем Енисее, жизнеобеспечение скитов было довольно скудным. Основу питания на Дубчесе долгое время составляла репа: «раньше (там)... даже картошки не было, в основном репу ели: печеную, вареную, жареную... При отце Тимофее у них рожь росла. А как стали с мира питаться (то есть, хлеб закупать), рожь расти перестала» (Мурашова, 2003: 207). Позже, когда специальным постановлением было разрешено употребление картофеля, на Дубчесе «стали картошку сажать... Но у них там такой Север, что приходится землю кострами обогревать. Они в мае месяце... садят, а к Успению уже все вырастает, потому что ночи светлые» (там же).

Клавдия Ивановна подтвердила, что при ней на Дубчесе

«сеяли рожь, а скота не держали... Отец Симеон говорил, что в монастыре не должно быть рождаемости - ни людской, ни скота, да и негде коров держать, земля мохом покрыта, выпасов нет - одно болото... Где полянка - (то место использовали) под посевы, посадки... Питались с огорода... (если) овощи среди лета замерзали... (то) поджигали бревно и землю оттаивали... Ягоды в тайге мало было, а рыбу не ловили, так как далеко от Дубчеса жили... Голодно было... Все сами делали / У каждого свои обязанности. Пожилые молились, молодые работали... Кто помоложе - на улице, старые - в жилье...» (ПМА, 2004 г., 2021 г., п. Сизим; Любимова, 2017: 127).

Тем не менее, у дубчесских скитников, как сказано в Урало-Сибирском патерике, была возможность хотя бы раз в год присутствовать на исповеди у духовного отца и совершать причастие - то главное, чего были лишены оставшиеся в миру единоверцы, от лица которых в сочинении приводится обращение к скитникам:

«Простите Господа ради нас и благодарите Бога, яко вы со отцами сподобились сожития. Хотя и трудна ваша жизнь, но и награда велика вам почестных даров, и при конце чистое исповедание, и Святых Таинъ причащение надежно и несумнительно. Наше же положение и исход от телесе слезен во всем» (УралоСибирский ..., 2014: 183).

Точно так же оставшаяся со своим скитом на Урале мать Македония (в миру - Мариамия Петровна) в письмах в Сибирь сетовала на то, что ее скитницам приходится жить без духовного попечения, терпеть преследования, притеснения:

«А здесь худо очень и нельзя жить более от находа людей всяких положений. Есть пытатели во овчине, ходят в дома християн с лестию, волцы суще внутрь, во одежде обычной и с брадою, выспрашивают пустынных жителей, ведущие все наше положение и древность. И простые им сказуют, а они пишут и шлют высочайшим, и последи что-то будет недобро. Блажен, кто удалился в пустынно местоположение и грядущего зла не узрит. Матери святии и все ваши юные трудницы... живите, готовящеся к небечи изшествию, и за нас, грешных, помолитеся» (там же: 183).

В свою очередь, старцы увещевали единоверцев не вступать в колхозы и не прельщаться прелестями мирской жизни. Обращаясь ко своему отцу Якову Лаптеву о. Симеон пишет:

«Вот ето меня зело опечалило, даже почти впадох во уныние. Ведь ты, дорогий старче, сам знаешь, что городская жизнь одного твоего погубила навечно. Ведь не помимо глаголет Писание: “Со избранным избран будеши, а со строптивым развратишися”... А в городе всеобдержно творится огорчение Бога. В нынешныя времена властели жизнию идут против Бога, на тож влекут и покоряющихся им... и чрез ето окажутся плевелы и пшеница разделенными. Плевелы, сиречь люди, нетвердые в вере... не понесут скорбей и напастей Бога ради, но выйдут... ис Церкви Христовой... И кто не входит в колхозы и в прочия артели, в которых потаптывается евангельская жизнь, но стоит крепко за правду евангильския... и таковаго мы считаем несомненным мучеником. К таковым относятся словеса Христовы сии: “Блаженни изгнани правды ради, яко тех есть царство небесное” (Духовная литература ..., 1999: 211).

Отметим, что вплоть до конца 1960-х гг. вся отчетная документация Енисейского района о темпах и масштабах охвата населения колхозами пестрела пометками о том, что вокруг очень незначительного их количества проживает и успешно хозяйствует единоличное население.

${ }^{1}$ Это свидетельство информанта, не нашедшее подтверждения в других источниках. Этот момент будет уточняться в дальнейших исследованиях. 
Вспоминая свою повседневную жизнь в монастыре, Клавдия Ивановна отмечает, что «жилье (там было) разное, об этом и говорить нечего» (ПМА, 2004 г., 2021 г., п. Сизим). Сама она была

«простой послушницей - что заставляли, то и делала... Лен садили, на снегу отбеливали, пряли, ткали, одежу шили... Хлеб сеяли, дрова зимой заготовляли... Все делали сами... трудно жили, но иначе зачем тогда монастырь, если все легко?», - задается вопросом наша собеседница (ПМА, 2004 г., 2021 г., п. Сизим).

На основе записанных в разные годы интервью мы воссоздали биографические нарративы информанта, сопоставимые с текстами «наивных мемуаров», которые используются в социальной психологии как источник для изучения с помощью контент-анализа фрагментов системы ценностей автора. Такая система, подчеркивает А. П. Минаева, является основой личности человека, однако ее исследование сопряжено с большими трудностями, поскольку она довольно редко осознается самим человеком, оставаясь скрытой от него самого (Минаева, 2001: 29-49).

Как правило, ценности носят эмоционально окрашенный характер, а их упоминание очень часто сопровождается определенными эмоциональными высказываниями. Следуя за А. П. Минаевой, мы предприняли попытку определить высказывания, вызывавшие наибольший эмоциональный отклик у нашей собеседницы. Одной из таких тем оказалась тема голода - «скудной жизни», которую ей пришлось прожить в таежном монастыре, расположенном в трехстах километрах от ближайшего населенного пункта: «В миру-то полегче жить... хоть сытые... всю молодость я прожила в монастыре, свету белого не видела» (ПМА, 2014 г., п. Сизим). Говоря о «страшных (последних) временах», Клавдия Ивановна снова затрагивает тему голода, убежденная в том, что с приходом антихриста «три года не будет дожжа, и воды, и хлеба тоже не будет... (а значит) нечего будет исть» (там же). «Сильно это страшно, - добавляет бывшая обитательница монастыря, - когда человек исть захочет... Он на все пойдет - хоть ему печать клади! А если он сытый, он к антихристу не пойдет...» (там же). И даже тюрьма, с точки зрения информанта, по сравнению с голодом являлась меньшим злом, поскольку в тюрьмах, по ее сведениям, людей кормили: «ой, шибко там, говорят, кормили. Потому что разузнали, что они (бывшие скитники, попавшие в тюрьму после разорения Дубчесских скитов), - невинные, ни за что их (с Дубчеса) вывезли... никакая это не банда. Просто жили и всё, Богу молились» (там же). Более того, Клавдия Ивановна уверена, что охранники, знавшие о том, что староверы соблюдают пост, спрашивали заключенных: «Что вам сёдни готовить? Постно или молосно?» (там же).

Известно, что старицы всерьез беспокоились о возможном распаде религиозных общин, поскольку не все выдерживали скитскую жизнь, бывали случаи возвращения в «мир». Обращаясь к юным послушницам, настоятели призывали их: «...помните и знайте, что вся ваша жизнь и ваше девство обручено небесному жениху... (которое вы не можете) преобручить земному жениху» (Урало-Сибирский ..., 2014: 194-195). Считалось, что все, посвятившие себя Богу, живущие в скиту и лишенные всякого общения с внешним миром, имеют больше шансов спасти душу, даже не совершая накрытия.

После разгрома скитов в 1951 г. бывшие послушники смогли разыскать своих родственников или переехать в другие тайные поселения. Сама Клавдия Ивановна уехала к матери в Ворогово, а вскоре они перебрались к единоверцам в Туву, где она вышла замуж и родила троих детей. Размышляя о своей возможной скитской судьбе, Клавдия Ивановна утверждает, что «...молодым никакой тягости (в монастырях) не было. Все шло своим чередом, (сама) ни о чем не задумывалась и о постриге не думала, (но если бы скит) не разогнали, может, такое таинство и свершилось бы» (ПМА, 2021 г., п. Сизим). Вместе с тем, уже в преклонные годы, Клавдия Ивановна, прожившая всю жизнь в миру, сделала попытку поселиться в скиту в Верховье, но не смогла там жить и вернулась назад в Сизим: «Это ведь знашь, каку силу иметь надоть?» (там же).

\section{Заключение}

Перед своей кончиной матушка Мастрадея обратилась к живущим в д. Солобоево единоверцам с посланием:

«Дорогие мои матушки и сестры Вера, Енафа и Евгения, ежели вы пошли Христа ради жить, то не место спасает человека, но человек место просвещает. Не держитесь за место, а держитеся за человека да за благословение. Благословенно свято, а не благословенно проклято» (Урало-Сибирский ..., 2014: 196).

Переселившиеся из Перми в Сибирь мирские и пустынножительные общины староверов-часовенных освоили во второй половине XX в. огромную территорию, доказав успешность своих хозяйственных практик. В ходе миграций они заложили основу современной поселенческой структуры ле- 
вобережья Енисея, сохранив общность хозяйственной, социальной и религиозной жизни дуальной связки «скит-деревня». В результате этих процессов сформировалось устойчивое конфессиональное пространство староверов, не знающее и не признающее иных границ, кроме сакральных. Пройдя через разорение 1951 г., Дубчесские скиты не просто сохранились, но сумели возродиться, переживая в настоящее время своеобразный ренессанс.

Несмотря на уникальный жизненный опыт Клавдии Ивановны Юрковой, которая оказалась в монастыре не в конце жизни, а в ее начале, в период своего физического, социально-психологического и религиозного становления, земная траектория ее жизненного пути, рассмотренная на фоне миграционных процессов единоверцев, может быть представлена в качестве проекции ее духовной жизни как пути к спасению.

\section{СПИСОК ЛИТЕРАТУРЫ}

Аргудяева, Ю. В. (2001) Старообрядцы Волго-Камья и Урала на Дальнем Востоке // Старообрядческий мир Волго-Камья: Проблемы комплексного изучения: материалы научной конференции / гл. ред. Г. Н. Чагин. Пермь : Пермский государственный университет. 264 с. С. 257-263.

Ваганов, Н. А. (1882) Хозяйственно-статистическое описание крестьянских волостей Алтайского округа. I. Барнаульский округ. II. Кузнецкий округ. III. Томский округ. IV. Бийский округ. Б. м.: б. и. 305 л.

Васильев, А. В., Ким, Е. А., Буркун, А. О. (2016) Карты Переселенческого управления и процессы освоения таежного Причулымья (1905-1918 гг.) // Былые годы. Т. 41. Вып. 3. С. 795-803.

Главацкая, Е. М. (2008) Религиозный ландшафт Урала: феномен, проблемы реконструкции, методы исследования // Уральский исторический вестник. № 4 (21). С. 76-82.

Герасимов А. (1991) Повесть о Дубчесских скитах / публ., коммент. и вступ. ст. Н. Н. Покровского // Новый мир. № 9. С. 91-103.

Данилко, Е. С. (2019) «Смерть ближе рубашки» похоронная обрядность старообрядцев-часовенных // Новые исследования Тувы. № 1. C. 44-59. DOI: https://doi.org/10.25178/nit.2019.1.4

Дутчак, Е. Е. (2006) Путь в Беловодье (к вопросу о современных возможностях и перспективах изучения конфессиональных миграций) // Вестник РУДН. Серия История России. № 1 (6). С. 81-94.

Дутчак, Е. Е. (2007) Из «Вавилона» в «Беловодье»: адаптационные возможности таежных общин староверовстранников (вторая половина XIX - начало XXI в.) / под ред. В. В. Керова. Томск : Изд-во Томского университета. 414 c.

Дутчак, Е. Е. (2011) Скитская колонизация Западной Сибири: общее и особенное // Книга и литература в культурном пространстве эпох (XI-XX века): сб. науч. статей / сост. и отв. ред. О. Н. Фокина, В. Н. Алексеев. Новосибирск : РИО ГПНТБ СО РАН. 1056 с. С. 949-961.

Дутчак, Е. Е., Васильев, А. В., Ким, Е. А., Полежаева, Т. В. (2013) Православный ландшафт таежной Сибири: концепция исследования // Сибирские исторические исследования. № 1. С. 79-90.

Дутчак, Е. Е., Ким, Е. А., Буркун, А. О. (2015) Крестьянская община и старообрядческий скит: формула притяжения // Православная культура вчера и сегодня / научн. редакция Е. Потехиной и А. Кравецкого. Центр Исследований Восточной Европы, Варминьско-Мазурского Университета в Ольштыне. Cep. II Fontes Slavia Orthodoxa. Olsztyn : Uniwersytetu Warmińsko-Mazurskiego w Olsztyni. 379 с. С. 235-251.

Духовная литература староверов востока России XVIII-XX вв. (1999) / подг. Н. Н. Покровским, Н. С. Гурьяновой, Н. Д. Зольниковой и др. Новосибирск : Сибирский хронограф. 799 с.

Журавель, О. Д. (2001) К изучению топики старообрядческой культуры: пустыня как святая земля // Гуманитарные науки в Сибири. № 3. С. 56-60.

Зольникова, Н. Д. (1998) Урало-сибирские староверы в первой половине XX в.: Древние традиции в советское время // История русской духовной культуры в рукописном наследии XVI-XX вв. / отв. ред. Е. К. Ромодановская. Новосибирск: Наука; Научно-издательский центр ОИГГС СО РАН. 316 с. С. 174-191.

Ламажаа, Ч. К. (2012) Концепты «За Саянами» и «тувинское время» в общественном дискурсе Тувы // Пограничье культур - культуры пограничья / научн. ред. 3. Морохоева. Debaty Artes Liberales. T. VI. Warszawa : Universytet Warszawski. 321 c. C. $279-293$.

Любимова, Г. В. (2004) Старообрядцы-часовенные верховьев Малого Енисея: традиции и новации // Проблемы межэтнического взаимодействия в Сибири / отв. ред. И. Н. Гемуев, А. А. Бадмаев. Новосибирск : Издательство АртИнфоДата. 112 с. С. 50-64.

Любимова, Г. В. (2017) Модернизация земледельческого труда в культуре сибирских старообрядцев // Уральский исторический вестник. № 2 (55). С. 122-130. 
Манькова, И. Л. (2008) Формирование православного ландшафта Зауралья в XVII в. // Уральский исторический вестник. № 4 (21). С. 83-97.

Минаева, А. П. (2001) «Наивные» мемуары В. М. Малькова: опыт контент-анализа // «Наивная литература»: исследования и тексты / сост. С. Ю. Неклюдов. М. : Моск. обществ. научн. фонд. 248 с. С. 29-49.

Мурашова, Н. С. (2003) Повествования священноинока Евагрия // Проблемы изучения этнической культуры восточныХ славян Сибири XVII-XX вв. / отв. ред. Ф. Ф. Болонев. Новосибирск : Агро-Сибирь. 259 с. С. $194-221$.

На путях из Земли Пермской в Сибирь: очерки этнографии северноуральского крестьянства XVII-XX вв. (1989) / В. А. Александров, И. В. Власова, И. А. Кремлева и др. М. : Наука. 352 с.

Покровский, Н. Н. (1991) За страницей «Архипелага ГУЛАГ» // Новый мир. № 9. С. 77-90.

Покровский, Н. Н. (1992) Скитские биографии // Новый мир. № 8. С. 193-210.

Покровский, Н. Н., Зольникова, Н. Д. (2002) Староверы-часовенные на востоке России в XVIII-XX вв.: Проблемы творчества и общественного сознания. М. : Памятники исторической мысли. 471 с.

Приль, Л. Н. (2001) Из земли Пермской в Сибирь с идеей самодостаточности // Старообрядческий мир ВолгоКамья: Проблемы комплексного изучения: материалы научной конференции / гл. ред. Г. Н. Чагин. Пермь : Пермский государственный университет. 264 с. С. 248-257.

Репина, Л. П. (2005) От «истории одной жизни» к «персональной истории» // История через личность. Историческая биография сегодня / отв. ред. Л. П. Репина. М. : Кругъ, 720 с. С. 55-74.

Сибирь и Русский Север: проблемы миграций и этнокультурных взаимодействий (XVII - начало XXI века) (2014) / Е. Ф. Фурсова, А. Б. Пермиловская, А. В. Черных и др. Новосибирск : Изд-во Института археологии и этнографии СО РАН. 296 с.

Стороженко, А. А. (2015) Конфессиональные миграции старообрядцев как канал межкультурного взаимодействия в Центральной Азии в XIX - начале XX в. // Старообрядчество: история и современность, местные традиции, русские и зарубежные связи: Материалы VI Международной научно-практической конференции / науч. ред. А. П. Майоров, отв. ред. С. В. Васильева. Улан-Удэ: Изд-во Бурятского гос. ун-та. 392 с. С. 130-136.

Стороженко, А. А. (2019) Старообрядческие монастыри «енисейского меридиана» в XX веке: истоки, традиции и современное состояние // Новые исследования Тувы. № 1. С. 4-15. DOI: https://doi.org/10.25178/nit.2019.1.1

Стороженко, А. А., Татаринцева, М. П. (2016) Верхнеенисейские старообрядческие скиты в Туве: историческая реконструкция // Научные труды Тувинского государственного университета. Материалы ежегодной научнопрактической конференции преподавателей, сотрудников и аспирантов ТувГУ, посвященной 65-летнему юбилею высшего педагогического образования в Туве и 95-летию становления Тувинской народной республики / отв. ред. У. В. Ондар. Кызыл : ФГБОУ ВО «Тувинский государственный университет». 228 с. С. 95-96.

Стороженко, А. А., Татаринцева, М. П. (2019) «Прекрасная пустыня, прими меня в свою частыню». Старообрядческие скиты в верховье Енисея // Традиционная культура. Т. 20. № 2. С. 88-97. DOI: https://doi.org/10.26158/ TK.2019.20.2.007

Татаринцева, М. П. (2006) Старообрядцы в Туве: историко-этнографический очерк. Новосибирск : Наука. 216 с.

Татаринцева, М. П., Стороженко, А. А. (2015) Старообрядцы Тувы: ретроспектива и современность. Saarbrucken : Lambert Academic Publishing. 137 c.

Урало-Сибирский патерик: тексты и комментарии (2014) : в 3 т. / отв. ред. Н. Н. Покровский. М. : Языки славянской культуры. Кн. 1 (Т. 1-2). 464 с.

Фурсова, Е. Ф. (2014) Крестьяне-старожилы и переселенцы юга Западной Сибири: севернорусский компонент в традиционной культуре (конец XIX - первая четверть XX века) // Сибирь и Русский Север: проблемы миграций и этнокультурных взаимодействий (XVII - начало XXI века) / Е. Ф. Фурсова, А. Б. Пермиловская, А. В. ЧерныХ и др. Новосибирск : Изд-во Института археологии и этнографии СО РАН. 296 с. С. 98-202.

Чагин, Г. Н. (1998) Заселение и хозяйственное освоение Верхокамья в конце XVIII - первой трети XX в. // Мир старообрядчества: живые традиции: результаты и перспективы комплексных исследований русского старообрядчества / отв. ред. И. В. Поздеева. М. : Российская политическая энциклопедия (РОССПЭН). Вып. 4. 463 с. C. 265-274.

Черных, А. В. (2001) Старообрядчество южных районов Пермской области в контексте этнокультурной истории //Старообрядческий мир Волго-Камья: Проблемы комплексного изучения: материалы научной конференции / гл. ред. Г. Н. Чагин. Пермь : Пермский государственный университет. 264 с. С. 133-159.

Чистов, К. В. (2002) Заметки об эскапизме и эсхатологических представлениях старообрядцев XVII-XIX вв. // Христианство в регионах мира / отв. ред. Т. А. Бернштам. СПб. : МАЭ РАН. 334 с. С. 179-193.

Дата поступления: 06.05.2021 2. 


\section{REFERENCES}

Argudiaeva, Yu. V. (2001) Staroobriadtsy Volgo-Kam'ia i Urala na Dal'nem Vostoke [Old Believers from the Volga-Kama region and from the Urals in the Far East]. In: Staroobriadcheskii mir Volgo-Kam'ia: Problemy kompleksnogo izucheniia [The Old Believers 'World of the Volga-Kama region: Problems of comprehensive studies]: proceedings of a research conference / ed. by G. N. Chagin. Perm’, Perm State University. 264 p. Pp. 257-263. (In Russ.).

Vaganov, N. A. (1882) Khoziaistvenno-statisticheskoe opisanie krest'ianskikh volostei Altaiskogo okruga. I. Barnaul'skii okrug. II. Kuznetskii okrug. III. Tomskii okrug. IV. Biiskii okrug [An economic and statistical description of peasant volosts of the Altai district. I. Barnaul district. II. Kuznetsky district. III. Tomsk district. IV. Biysk district]. S. 1., s. n. 305 p. (In Russ.).

Vasil'ev, A. V., Kim, E. A. and Burkun, A. O. (2016) Karty Pereselencheskogo upravleniia i protsessy osvoeniia taezhnogo Prichulym'ia (1905-1918 gg.) [Maps of the Resettlement Administration and the colonization process in Tomsk-Chulym taiga (1905-1918)]. Bylye gody, vol. 41, issue 3, pp. 795-803. (In Russ.).

Glavatskaia, E. M. (2008) Religioznyi landshaft Urala: fenomen, problemy rekonstruktsii, metody issledovaniia [Religious landscape of the Urals: phenomenon, reconstruction, methodology]. Ural'skii istoricheskii vestnik, no. 4 (21), pp. 76-82. (In Russ.).

Gerasimov A. (1991) Povest' o Dubchesskikh skitakh / publ., komment. i vstup. st. N. N. Pokrovskogo [The story of the Dubchessky sketes / publ., comment. and introd. by N. N. Pokrovsky]. Novyi mir, no. 9, pp. 91-103. (In Russ.).

Danilko, E. S. (2019) «Smert' blizhe rubashki» pokhoronnaia obriadnost' staroobriadtsev-chasovennykh [«Death is closer than a shirt»: Funeral ceremonialism of Chasovennye (“Chapel-going”) Old Believers]. New Research of Tuva, no. 1, pp. 44-59. (In Russ.). DOI: https://doi.org/10.25178/nit.2019.1.4

Dutchak, E. E. (2006) Put' v Belovod'e (k voprosu o sovremennykh vozmozhnostiakh i perspektivakh izucheniia konfessional'nykh migratsii) [The road to the Belovod'e: contemporary prospects of studying confessional migrations]. Vestnik RUDN. Seriia Istoriia Rossii, no. 1 (6), pp. 81-94. (In Russ.).

Dutchak, E. E. (2007) Iz «Vavilona»v «Belovod'e»: adaptatsionnye vozmozhnosti taezhnykh obshchin staroverov-strannikov (vtoraia polovina XIX - nachalo XXI v.) [From "Babylon" to "Belovodye": adaptation of taiga communities of Old Believerswanderers in later $19^{\text {th }}$ and early $20^{\text {th }}$ century] / ed. by V. V. Kerova. Tomsk, Tomsk University Publishing House. 414 p. (In Russ.).

Dutchak, E. E. (2011) Skitskaia kolonizatsiia Zapadnoi Sibiri: obshchee i osobennoe [The Skete colonization of Western Siberia: general and special aspects]. In: Kniga i literatura $v$ kul'turnom prostranstve epokh (XI-XX veka) [Book and literature in the cultural space of epochs: $11^{\text {th }}$ to $20^{\text {th }}$ century]: a collection of scientific articles / comp. and ed. by O. N. Fokin and V. N. Alekseev. Novosibirsk, RIO GPNTB SO RAN. 1056 p. Pp. 949-961. (In Russ.).

Dutchak, E. E., Vasil'ev, A. V., Kim, E. A. and Polezhaeva, T. V. (2013) Pravoslavnyi landshaft taezhnoi Sibiri: kontseptsiia issledovaniia [Orthodox landscape of Siberian taiga region: the concept of research]. Siberian Historical Research, no. 1, pp. 79-90. (In Russ.).

Dutchak, E. E., Kim, E. A. and Burkun, A. O. (2015) Krest'ianskaia obshchina i staroobriadcheskii skit: formula pritiazheniia [The peasant community and the Old Believers' skete: the formula of attraction]. In: Pravoslavnaia kul'tura vchera i segodnia [Orthodox culture yesterday and today] / ed. by E. Potekhin and A. Kravetskii. Issue II. Fontes Slavia Orthodoxa. Olsztyn, Uniwersytetu Warmińsko-Mazurskiego w Olsztyni. 379 p. Pp. 235-251. (In Russ.).

Dukhovnaia literatura staroverov vostoka Rossii XVIII-XX vv. [Spiritual literature of the Old Believers of the East of Russia of the XVIII-XX centuries] (1999) / prep. by N. N. Pokrovskii, N. S. Gur'ianova, N. D. Zol'nikova et al. Novosibirsk, Sibirskii khronograf. 799 p. (In Russ.).

Zhuravel', O. D. (2001) K izucheniiu topiki staroobriadcheskoi kul'tury: pustynia kak sviataia zemlia [On the study of the topic of Old Believer culture: the desert as a holy land]. Gumanitarnye nauki v Sibiri, no. 3, pp. 56-60. (In Russ.).

Zol'nikova, N. D. (1998) Uralo-sibirskie starovery v pervoi polovine XX v.: Drevnie traditsii v sovetskoe vremia [Old Believers of the Urals and Siberia in the first half of the $20^{\text {th }}$ century: Old traditions in the Soviet era]. In: Istoriia russkoi dukhovnoi kul'tury v rukopisnom nasledii XVI-XX vv. [The history of Russian spiritual culture in the manuscript heritage of the $16^{\text {th }}-20$ th centuries] / ed. by E. K. Romodanovskaia. Novosibirsk, Nauka; Nauchno-izdatel'skii tsentr OIGGS SO RAN. 316 p. Pp. 174-191. (In Russ.).

Lamazhaa, Ch. K. (2012) Kontsepty «Za Saianami» i «tuvinskoe vremia»v obshchestvennom diskurse Tuvy [The concepts of "Beyond the Sayans" and "Tuvan time" in the public discourse of Tuva]. In: Pogranich'e kul'tur - kul'tury pogranich'ia [Borderlands between cultures - cultures of the borderlands]. Ed. by Z. Morokhoeva / Debaty Artes Liberales. T. VI. Warszawa, Universytet Warszawski. 321 p. Pp. 279-293. (In Russ.).

Liubimova, G. V. (2004) Staroobriadtsy-chasovennye verkhov'ev Malogo Eniseia: traditsii i novatsii [Chasovennye Old Believers in the upper reaches of the Small Yenisei: traditions and innovations]. In: Problemy mezhetnicheskogo vzaimodeistviia $v$ Sibiri [Problems of interethnic interaction in Siberia]. Ed. by I. N. Gemuev and A. A. Badmaev. Novosibirsk, Izdatel'stvo ArtInfoData. 112 p. Pp. 50-64. (In Russ.).

Liubimova, G. V. (2017) Modernizatsiia zemledel'cheskogo truda v kul'ture sibirskikh staroobriadtsev [Modernization of agricultural labour in the culture of Siberian Old Believers]. Ural Historical Journal, no. 2 (55), pp. 122-130. (In Russ.). 
Man’kova, I. L. (2008) Formirovanie pravoslavnogo landshafta Zaural'ia v XVII v. [Forming the Russian orthodox landscape in the 17th century Urals]. Ural Historical Journal, no. 4 (21), pp. 83-97. (In Russ.).

Minaeva, A. P. (2001) «Naivnye» memuary V. M. Mal'kova: opyt kontent-analiza [V. M. Malkov’s “naïve” memoirs: an attempt at content analysis]. In: «Naivnaia literatura»: issledovaniia i teksty ["Naive literature": studies and texts] / sost. S. Yu. Nekliudov. Moscow, Mosk. obshchestv. nauchn. fond. 248 p. Pp. 29-49. (In Russ.).

Murashova, N. S. (2003) Povestvovaniia sviashchennoinoka Evagriia [The narratives of hieromonk Evagrius]. In: Problemy izucheniia etnicheskoi kul'tury vostochnykh slavian Sibiri XVII-XX vv. [Problems of studying the ethnic culture of the Eastern Slavs of $17^{\text {th }}-20^{\text {th }}$ century Siberia] / ed. by F. F. Bolonev. Novosibirsk, Agro-Sibir'. 259 p. Pp. 194-221. (In Russ.).

Na putiakh iz Zemli Permskoi v Sibir': ocherki etnografii severnoural'skogo krest'ianstva XVII-XX vv. [On the roads from the Perm Land to Siberia: essays on the ethnography of the Northern Ural peasantry of the $17^{\text {th }}-20^{\text {th }}$ centuries] (1989) / V. A. Aleksandrov, I. V. Vlasova, I. A. Kremleva et al. Moscow, Nauka. 352 p. (In Russ.).

Pokrovskii, N. N. (1991) Za stranitsei «Arkhipelaga GULAG» [Beyond the page of the GULAG Archipelago"]. Novyi mir, no. 9, pp. 77-90. (In Russ.).

Pokrovskii, N. N. (1992) Skitskie biografii [Skete biographys]. Novyi mir, no. 8, pp. 193-210. (In Russ.).

Pokrovskii, N. N. and Zol'nikova, N. D. (2002) Starovery-chasovennye na vostoke Rossii v XVIII-XX vv. : Problemy tvorchestva i obshchestvennogo soznaniia [Old believers of the Chasovennoye accord in the East of Russia in the 18th-20th centuries: Problems of creativity and public consciousness]. Moscow, Pamiatniki istoricheskoi mysli. 471 p. (In Russ.).

Pril', L. N. (2001) Iz zemli Permskoi v Sibir's ideei samodostatochnosti [From the Permian land to Siberia with the idea of self-sufficiency]. In: Staroobriadcheskii mir Volgo-Kam'ia: Problemy kompleksnogo izucheniia [The Old Believers 'World of the Volga-Kama region: Problems of comprehensive studies]: proceedings of a research conference / ed. by G. N. Chagin. Perm', Perm State University. 264 p. Pp. 248-257. (In Russ.).

Repina, L. P. (2005) Ot «istorii odnoi zhizni» k «personal'noi istorii» [From "history of a life” to "personal history"]. In: Istoriia cherez lichnost'. Istoricheskaia biografiia segodnia [History through personality: Historical biography today] / ed. by L. P. Repina. Moscow, Krug. 720 p. Pp. 55-74. (In Russ.).

Sibir' i Russkii Sever: problemy migratsii i etnokul'turnykh vzaimodeistvii (XVII - nachalo XXI veka) [Siberia and the Russian North: problems of migration and ethno-cultural interactions from the $17^{\text {th }}$ to the turn of the 21st century] (2014) / E. F. Fursova, A. B. Permilovskaia, A. V. Chernykh et al. Novosibirsk, Institute of Archeology and Ethnography SB RAS. 296 p. (In Russ.).

Storozhenko, A. A. (2015) Konfessional'nye migratsii staroobriadtsev kak kanal mezhkul'turnogo vzaimodeistviia v Tsentral'noi Azii v XIX - nachale XX v. [Confessional migrations of Old Believers as a channel of intercultural interaction in Central Asia in the 19th - early 20th centuries]. In: Staroobriadchestvo: istoriia i sovremennost', mestnye traditsii, russkie i zarubezhnye sviazi [Old Belief: history, modernity and local traditions, Russian and foreign relations]: Proceedings of the 6th International scientific and practical conference / ed. by A. P. Maiorov and S. V. Vasil'eva. Ulan-Ude, Izd-vo Buriatskogo gos. un-ta. 392 p. Pp. 130-136. (In Russ.).

Storozhenko, A. A. and Tatarintseva, M. P. (2016) Verkhneeniseiskie staroobriadcheskie skity v Tuve: istoricheskaia rekonstruktsiia [Upper Yenisei Old Believer monasteries in Tuva: a historical reconstruction]. In: Nauchnye trudy Tuvinskogo gosudarstvennogo universiteta [Scientific works of Tuva state University]. Proceedings of the annual scientific and practical conference of teachers, staff and postgraduates of TUVSU dedicated to the 65th anniversary of higher pedagogical education in Tuva and the 95th anniversary of the formation of the Tuvan People's Republic / ed. by U. V. Ondar. Kyzyl, Tuvan State University. 228 p. Pp. 95-96. (In Russ.).

Storozhenko, A. A. (2019) Staroobriadcheskie monastyri «eniseiskogo meridiana»v XX veke: istoki, traditsii i sovremennoe sostoianie [Old Belief monasteries of the «Yenisei meridian» in the 20th century: origins, traditions and current state]. New Research of Tuva, no. 1, pp. 4-15. (In Russ.). DOI: https://doi.org/10.25178/nit.2019.1.1

Tatarintseva, M. P. (2006) Staroobriadtsy v Tuve: istoriko-etnograficheskii ocherk [Old Believers in Tuva: a historical and ethnographic essay]. Novosibirsk, Nauka. 216 p. (In Russ.).

Tatarintseva, M. P. and Storozhenko, A. A. (2015) Staroobriadtsy Tuvy: retrospektiva i sovremennost' [The Old Believers of Tuva: the past and present]. Saarbrucken: Lambert Academic Publishing. 137 p. (In Russ.).

Tatarintseva, M. P., Storozhenko, A. A. (2019) «Prekrasnaia pustynia, primi menia v svoiu chastyniu». Staroobriadcheskie skity v verkhov'e Eniseia ["Oh, delightful skete, accept and protect me from worldly life!" Old Believer sketes on the upper Yenisei]. Traditsionnaia kul'tura, vol. 20, no. 2, pp. 88-97. (In Russ.). DOI: https://doi.org/10.26158/TK.2019.20.2.007

Uralo-Sibirskii paterik: teksty i kommentarii [The Ural-Siberian Patericon: texts and commentary] (2014) : in 3 vols. / ed. by N. N. Pokrovskii. Moscow, Iazyki slavianskoi kul'tury. Book 1 (Vol. 1-2). 464 p. (In Russ.).

Fursova, E. F. (2014) Krest'iane-starozhily i pereselentsy iuga Zapadnoi Sibiri: severnorusskii komponent v traditsionnoi kul'ture (konets XIX - pervaia chetvert' XX veka) [Old-timers and migrants in the south of Western Siberia: the Northern Russian component in traditional culture from the end of the $19^{\text {th }}$ to the first quarter of the XX century)]. In: Sibir' i Russkii Sever: problemy migratsii i etnokul'turnykh vzaimodeistvii (XVII - nachalo XXI veka) [Siberia and the Russian 
North: problems of migration and ethno-cultural interactions from the 17th to the turn of the 21st century] / E. F Fursova, A. B. Permilovskaia, A. V. Chernykh et al. Novosibirsk, Publishing house of the Institute of Archeology and Ethnography SB RAS. 296 p. Pp. 98-202. (In Russ.).

Chagin, G. N. (1998) Zaselenie i khoziaistvennoe osvoenie Verkhokam'ia v kontse XVIII - pervoi treti XX v. [The settlement and economic development of the Upper Kama from the late $18^{\text {th }}$ to the first third of the $20^{\text {th }}$ century]. In: Mir staroobriadchestva: zhivye traditsii: rezul'taty i perspektivy kompleksnykh issledovanii russkogo staroobriadchestva [The world of Old Believers: living traditions: results and prospects of comprehensive studies of Russian Old Believers] / ed. by I. V. Pozdeeva. Moscow, Rossiiskaia politicheskaia entsiklopediia (ROSSPEN). Vol. 4. 463 p. Pp. 265-274. (In Russ.).

Chernykh, A. V. (2001) Staroobriadchestvo iuzhnykh raionov Permskoi oblasti v kontekste etnokul'turnoi istorii [The Old Believers of the Southern districts of the Perm region in the context of ethnocultural history]. In: Staroobriadcheskii mir Volgo-Kam'ia: Problemy kompleksnogo izucheniia [The Old Believers 'World of the Volga-Kama region: Problems of comprehensive studies]: proceedings of a research conference / ed. by G. N. Chagin. Perm', Perm State University. 264 p. Pp. 133-159. (In Russ.).

Chistov, K. V. (2002) Zametki ob eskapizme i eskhatologicheskikh predstavleniiakh staroobriadtsev XVII-XIX vv. [Notes on escapism and eschatological representations of Old Believers in the $17^{\text {th }}-19^{\text {th }}$ centuries]. In: Khristianstvo $v$ regionakh mira [Christianity in the regions of the world] / ed. by T. A. Bernshtam. St. Petersburg, MAE RAN. 334 p. Pp. 179-193. (In Russ.).

Submission date: 06.05.2021. 